
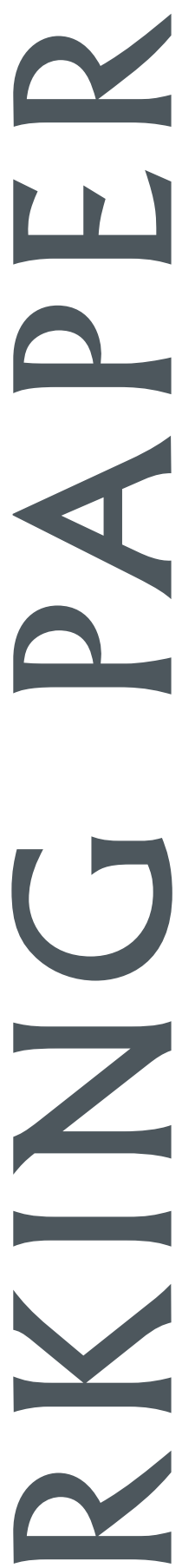

EAST-WEST CENTER 
The U.S. Congress established the East-West Center in 1960 to foster mutual understanding and cooperation among the governments and peoples of the Asia Pacific region including the United States. Funding for the Center comes from the U.S. government with additional support provided by private agencies, individuals, corporations, and Asian and Pacific governments.

East-West Center Working Papers are circulated for comment and to inform interested colleagues about work in progress at the Center.

For more information about the Center or to order publications, contact:

Publication Sales Office

East-West Center

1601 East-West Road

Honolulu, Hawaii 96848-1601

Telephone: 808-944-7145

Facsimile: 808-944-7376

Email: ewcbooks@EastWestCenter.org

Website: www.EastWestCenter.org 


\title{
Transnational Communities and the Evolution of Global Production Networks: The Cases of Taiwan, China, and India
}

\author{
AnnaLee Saxenian
}

\begin{abstract}
AnnaLee Saxenian is a Professor in the School of Information Management and Systems and the Department of City and Regional Planning at the University of California at Berkeley. She is a member of the California Council on Science and Technology, an Adjunct Fellow at the Institute for the Future, and a Senior Research Fellow at the Center for Research on Entrepreneurship at Tsinghua University in China. Her recent books include Silicon Valley's New Immigrant Entrepreneurs (Public Policy Institute of California, 1999) and Regional Advantage: Culture and Competition in Silicon Valley and Route 128 (Harvard University Press).

Forthcoming in Industry and Innovation, Vol. 9, No. 2 (August 2002) Special Issue, Global Production Networks, Information Technology, and Local Capabilities by Dieter Ernst and Linsu Kim (guest editors).

East-West Center Working Papers: Economics Series is an unreviewed and unedited prepublication series reporting on research in progress. The views expressed are those of the author and not necessarily those of the Center. Please direct orders and requests to the East-West Center's Publication Sales Office. The price for Working Papers is $\$ 3.00$ each plus postage. For surface mail, add $\$ 3.00$ for the first title plus $\$ 0.75$ for each additional title or copy sent in the same shipment. For airmail within the U.S. and its territories, add $\$ 4.00$ for the first title plus $\$ 0.75$ for each additional title or copy in the same shipment. For airmail elsewhere, add $\$ 7.00$ for the first title plus $\$ 4.00$ for each additional title or copy in the same shipment.
\end{abstract}




\begin{abstract}
Endogenous growth theory has recently originated in economics. Building on this theory, this chapter conceptualizes the phenomenon of endogenous growth in terms of some new ideas developed in the field of international business (IB). These ideas have so far been not linked to the notion of endogenous growth. On the other hand, mainstream economics has not made much progress in exploring the MNC-government relationships through which growth-inducing "mechanics" are created, a topic of great importance and research in the IB-related discipline. Both MNCs and governments complement each other in facilitating an efficient matching of ownership-specific assets (notably knowledge) with location-specific advantages, thereby enabling the developing host countries to realize potential growth in an intensified manner, a new mode of endogenous growth that counteracts the law of diminishing returns. The phenomenon of MNC-cum-government-driven endogenous growth is thus conceptualized.
\end{abstract}


Transnational entrepreneurs-US-educated immigrant engineers whose activities span national borders - are creating new economic opportunities for formerly peripheral economies around the world. Talented immigrants who have studied and worked in the US are increasingly reversing the "brain drain" by returning to their home countries to take advantage of promising opportunities there. In so doing they are building technical communities that link their home countries to one of the world's leading centers of information and communications technologies, Silicon Valley. As the "brain drain" increasingly gives way to a process of "brain circulation," networks of scientists and engineers are transferring technology, skill, and know-how between distant regional economies faster and more flexibly than most corporations.

The development of technical communities that span national borders and boast as shared assets technical information, trust, and contacts have been largely overlooked in most accounts of globalization. This paper suggests that transnational communities may become as important as more commonly recognized actors - states and multinational corporations - in the growth of new centers of technology entrepreneurship. Moreover, these communities have the potential to play an increasingly important role in the evolution of global production networks. Transnational entrepreneurs and their communities provide a significant mechanism for the international diffusion of knowledge and the creation and upgrading of local capabilities--one that is distinct from, but complementary to, global production networks.

The first half of the paper analyzes the economic and technological context for the emergence of transnational communities and outlines their contributions to the emergence and upgrading of suppliers and nodes in global production networks.

The paper then examines the cases of Taiwan, India and China in detail to illustrate how technical communities both complement and accelerate the development of international 
production networks. In Taiwan, a "reversal" of the brain drain fuelled the growth of a of transnational community that has created new sources of supply as well as contributing directly to the subsequent upgrading of local capabilities--thereby insuring Taiwan's position as a supplier of high value-added, design intensive components. The Taiwanese case also illustrates how innovations seeded by transnational entrepreneurs have the potential to disrupt established hierarchies of suppliers.

Both India and China boast large numbers of US-educated scientists and engineers and in each case well-developed ethnic professional communities have built economic and social bridges to their home countries. The Indian network has contributed to the emergence of a globally competitive software services industry, however there is little evidence of the return entrepreneurship that could accelerate the upgrading of India's capabilities. In China, by contrast, policymakers have aggressively courted return entrepreneurs from the US, with notable successes. Most striking is the merging of the Taiwanese and Mainland Chinese transnational communities--particularly in the semiconductor industry--through shared roots in Silicon Valley's professional and technical networks. This could have a lasting impact on the development of China.

The paper concludes with speculations about the changing relationship between transnational technical communities and global production networks as well as some thoughts about directions for future research.

\section{Technical Communities and Industrial Decentralization}

Transnational technical communities are only possible because of advances in communication and transportation technologies and changes in the structure of technology 
markets and competition. In the 1960s and 1970s, the dominant competitors in the computer industry were vertically integrated corporations that controlled all aspects of hardware and software production (the IBM or "national champion" model.) The rise of an alternative industrial model (the Silicon Valley model) spurred the introduction of the personal computer and initiated a radical shift to a more fragmented industrial structure organized around networks of increasingly specialized producers.

Today, independent enterprises produce all of the components that were once internalized within a single large corporation-from application software, operating systems and computers to microprocessors and other components. The final systems are in turn marketed and distributed by still other enterprises. Within each of these horizontal segments there is, in turn, increasing specialization of production and a deepening social division of labor. In the semiconductor industry, for example, independent producers specialize in chip design, fabrication, packaging, testing, as well as different segments of the manufacturing materials and equipment sector. A new generation of firms has in turn emerged in the late 1990s that specializes in providing intellectual property in the form of design modules rather than the entire chip design.

This change in industry structure appears as a shift to market relations. The number of actors in the industry has increased dramatically and competition within many (but not all) horizontal layers has increased as well. Yet this is far from the classic auction market mediated by price signals alone; the decentralized system depends heavily on the coordination provided by cross cutting social structures and institutions. While Silicon Valley’s entrepreneurs innovate in increasingly specialized niche markets, intense communications in turn insure the speedy, often unanticipated, recombination of these specialized components into changing end products. This decentralized system provides significant advantages over a more integrated model in a volatile 
environment because of the speed and flexibility as well as the conceptual advances associated with the process of specialization and recombination.

The deepening social division of labor in the industry creates opportunities for innovation in formerly peripheral regions - opportunities that did not exist in an era of highly integrated producers. The vertical specialization associated with the new system continually generates entrepreneurial opportunities. By exploiting these opportunities in their home countries, transnational entrepreneurs can build independent centers of specialization and innovation, while simultaneously maintaining ties to Silicon Valley to monitor and respond to fast-changing and uncertain markets and technologies. They are also well positioned to establish cross-regional partnerships that facilitate the integration of their specialized components into end products.

The social structure of a technical community thus appears essential to the organization of production at the global as well as the local level. In the old industrial model, the technical community was primarily inside of the corporation. The firm was seen as the privileged organizational form for the creation and internal transfer of knowledge, particularly technological know-how that is difficult to codify. In regions like Silicon Valley, where the technical community transcends firm boundaries, however, such tacit knowledge is often transferred through informal communications or the inter-firm movement of individuals. This suggests that the multinational corporation may no longer be the advantaged or preferred organizational vehicle for transferring knowledge or personnel across national borders. Transnational communities provide an alternative and often more flexible and responsive mechanism for long distance transfers of skill and know-how_particularly between very different business cultures or environments. 
In fact, as recently as the 1970s, only the world's largest corporations had the resources and capabilities to grow internationally. These multinational corporations expanded primarily by establishing marketing offices or branch plants overseas. Today, by contrast, new transportation and communications technologies allow even the smallest firms to build partnerships with foreign producers and tap overseas expertise, cost-savings, and markets. Start-ups in Silicon Valley today are often global actors from the day they begin their operations. Many raise capital from Asia, others subcontract manufacturing to Taiwan or rely on software development in India, and virtually all seek to eventually sell their products in Asian markets.

The scarce resource in this new environment is the ability to locate foreign partners quickly and to manage complex business relationships across cultural and linguistic boundaries. This is particularly a challenge in high-technology industries in which products, markets, and technologies are continually being redefined - and where product cycles are routinely as short as six months.

First-generation immigrants, like the Chinese and Indian engineers of Silicon Valley, who have the language and cultural as well as the technical skills to function well in both the United States and foreign markets are distinctly positioned to play a central role in this environment. By becoming transnational entrepreneurs, these immigrants can provide the critical contacts, information, and cultural know-how that link dynamic—but distant—regions in the global economy. They can create social networks that enable even the smallest producers to locate and maintain mutually beneficial collaborations across great distances and facilitate access to foreign sources of capital, technical skills, and markets. The proliferation of such relationships over time can result in the creation of a transnational technical community—one 
that can transfer the market and technological know-how needed to support a dynamic of industrial upgrading.

\section{Technical Communities and Global Production Networks}

It is no coincidence that transnational technical communities have emerged as central actors in the world economy at the same time that global production networks (GPN) are increasingly replacing multinational firms with their stand-alone overseas investments (Ernst and Kim, 2001.) Communities of technically skilled immigrants with business experience and connections in the US are ideally positioned to accelerate the diversification and technical upgrading of supplier networks in their home countries, and as entrepreneurs they can also facilitate the emergence of new sources of supply and/or destabilize established hierarchies in global production networks.

Transnational communities thus play an important and complementary role to 'network flagships' in global production networks. US-educated returnees provide a direct mechanism for transferring the skill and tacit knowledge that can dramatically accelerate industrial upgrading in their developing countries. In addition they frequently coordinate relationships between the network flagships and suppliers, particularly when they are based in regions with differing languages and business cultures. This role ranges from helping to identify appropriate OEM suppliers to facilitating the ongoing (and often face-to-face) inter-firm communications required by rapid the pace of change in the industry.

Transnational communities likewise provide a mechanism for seeding entirely new centers of low-cost (at least initially) supply in less developed regions. Taiwan's leading personal computers suppliers, including Acer, Mitac, and Compeq, for example, got their initial contracts 
for IBM-compatible PCs in the early 1980s from Chinese entrepreneurs in Silicon Valley. Senior Indian engineers in large U.S. corporations were similarly among the first to outsource software services to India, thereby helping to establish the reputation and credibility of producers in regions like Bangalore. Over time, if transnational business connections deepen and expand they can accelerate the upgrading of the technical capabilities in these locales.

Finally, transnational entrepreneurs are well positioned to identify new market opportunities in global production networks--and even to innovate and destabilize established hierarchies of production. When Morris Chang returned from the US to pioneer the foundry model at Taiwan Semiconductor Manufacturing Corporation, he accelerated the vertical fragmentation of semiconductor production and made it possible for chip designers and intellectual property producers all over the world become part of international production networks in electronics. It also enabled a start-up like Taiwan's Via Technologies to threaten Intel's position in low-end microprocessors.

TSMC quickly became a world-class chip manufacturer because it was able to continue attracting experienced Taiwanese semiconductor engineers and managers from Silicon Valley. The Taiwanese transnational community also coordinated the ongoing relationships between TSMC and its US-based equipment suppliers (like Applied Materials) and its customers (both small chip designers and more established producers.) In short, transnational technical communities can serve as important mechanisms for the coordination, upgrading, and transformation of global production networks.

\section{Transnational Entrepreneurs and Industrial Upgrading in Taiwan}

The experience of Taiwan illustrates how a transnational community contributes to both the creation and upgrading of nodes in global production networks. In the 1960s and 1970s, the 
relationship between Taiwan and the US was a textbook First-Third-world relationship. US businesses invested in Taiwan to take advantage of its low-wage manufacturing labor. Meanwhile the best and the brightest Taiwanese engineering students came to the US for graduate education and created a classic "brain drain" when they chose to remain pursue professional opportunities in the US. In fact, Taiwan sent more doctoral candidates in science and engineering to the US during the 1980s than any other country, including entire graduating classes from Taiwan's most elite engineering universities: National Taiwan University, National Chiaotung University, and Tsinghua University. See Figure 3.

This relationship changed dramatically in the late 1980s. Many of these US-educated engineers began to return home, drawn by active government recruitment and the opportunities created by rapid economic development. The upgrading of Taiwan's technological infrastructure and capacities in through rapidly growing OEM ties to foreign customers as well as through local learning-by-doing, spurred a reversal of the brain drain (See Figure 1.) At the same time a growing cohort of highly mobile engineers began to work in both the US and Taiwan, commuting across the Pacific regularly. Typically Taiwan-born, US-educated engineers, these "astronauts" have the professional contacts and language skills to function fluently in both the Silicon Valley and Taiwanese business cultures and to draw on the complementary strengths of the two regional economies. 


\section{Figure 1. Returnees to Taiwan from the US: 1970-1997}

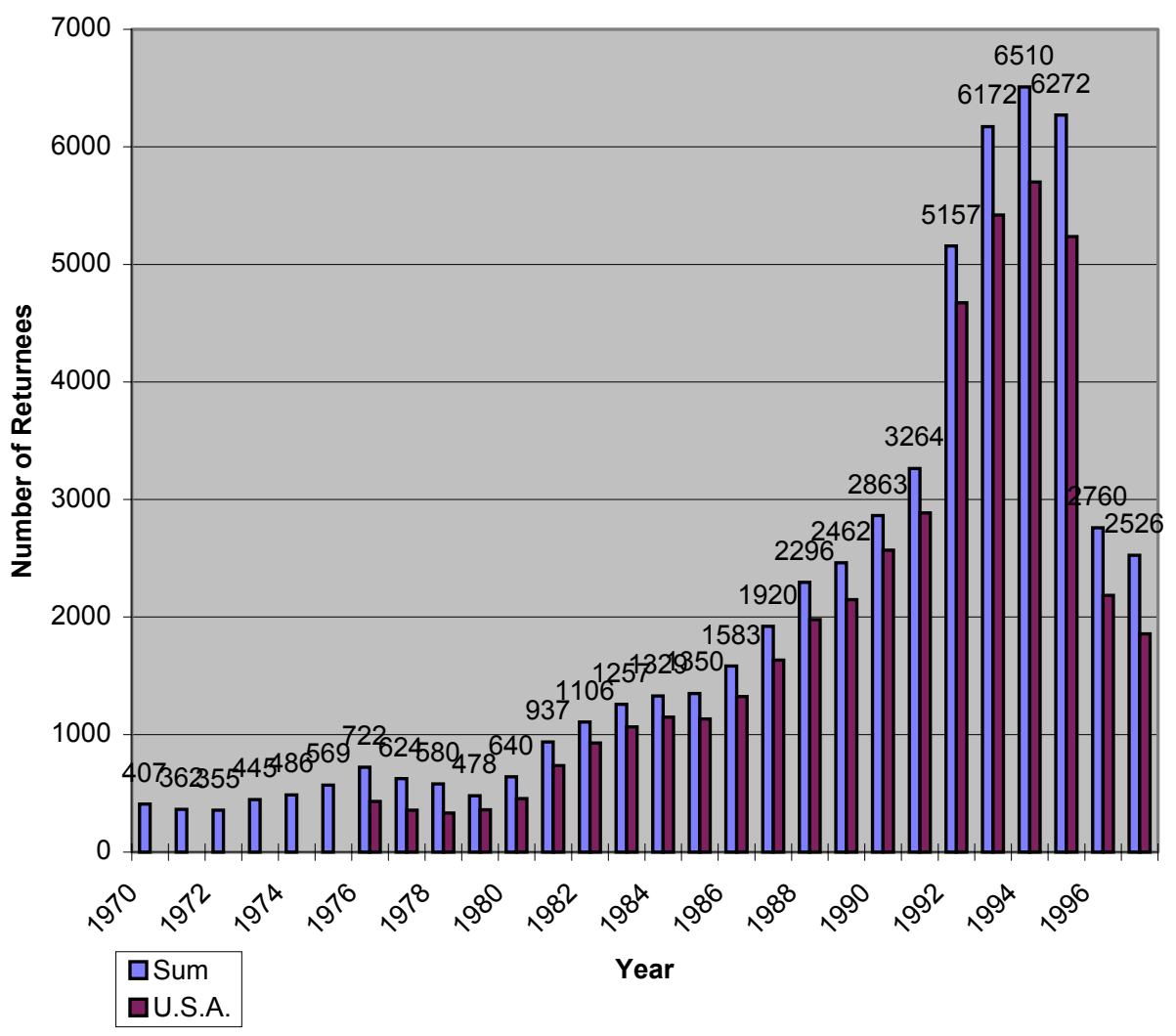

Source: National Youth Commission, Taiwan.

Miin $\mathrm{Wu}$ is a classic transnational entrepreneur. Wu immigrated to the US in the early 1970s to pursue graduate training in electrical engineering. After earning a doctorate from Stanford University in 1976, Wu recognized that there were no opportunities to use his new skills in economically backward Taiwan and remained in the US, working for more than a decade in senior positions at Silicon Valley-based semiconductor companies including Siliconix and Intel. He also gained entrepreneurial experience as one of the founding members of VLSI Technology. By the late 1980s, when economic conditions in Taiwan had improved Wu returned home to start his own semiconductor company, Macronix Co. He located the firm in the Hsinchu 
Science-based Industrial Park and brought 30 senior Silicon Valley engineers, mainly former classmates and friends, with him. In 1995, Macronix went public on the Taiwan stock exchange and the following year became the first Taiwanese company to list on NASDAQ.

While the Hsinchu Science Park was not the cause of Taiwan's successes in information technology industries, its success reflects the fast expanding ties between the two regions. After its first eight years (1980-88) the Park was home to only 94 companies with under $\$ 2$ billion in annual sales collectively and attracted only a handful of US-educated engineers annually. By the early 1990s the Park had become a destination for hundreds of returnees each year--and they started new companies at an accelerating rate. By 1989, 2,840 Taiwanese had returned from the US to work in the Hsinchu Science Park. And these returnees were disproportionately likely to start their own companies. Some $40 \%$ of the companies located in the Science Park (110 companies out of a total of 284) in 1999 were started by US-educated engineers, many of whom had considerable managerial or entrepreneurial experience in Silicon Valley. These returnees in turn actively recruited former colleagues and friends from Silicon Valley to return to Taiwan.

The Park was attractive to engineers from the US in part because of its location close to the headquarters of Taiwan's leading public research institute, Industrial Technology and Research Institute (ITRI) and its subsidiary, the Electronics Research and Service Organization (ERSO) which in the 1980s spearheaded a technological leapfrogging through the governmentled acquisition of semiconductor manufacturing technology from the U.S. Hsinchu is also the home of two of Taiwan's leading engineering universities which had dramatically increased enrollments and research capacity in the 1970s and 1980s. Finally, the Hsinchu Science Park offered a range of fiscal incentives for qualified technology investments and provided returnees 
with preferential access to scarce, high quality housing and to the only Chinese-American school in Taiwan — both of which are located on the park grounds. ${ }^{1}$

In addition to permanent returnees like $\mathrm{Wu}$, a growing population of "astronauts" works in both places and spends much of their lives on airplanes. While their families may be based on either side of the Pacific (most often they stay in California because of the lifestyle advantages), these engineers travel between Silicon Valley and Hsinchu once or even twice a month, taking advantage of the opportunities to play middlemen bridging the two regional economies. This includes many Taiwanese angel investors and venture capitalists as well as executives and engineers from companies like Macronix with activities in the two regions.

This lifestyle is, of course, only possible because of the improvements in transportation and communications technologies. However it does not mean these "astronauts" are rootless. Their dense personal networks and intimate local knowledge of both Silicon Valley and Hsinchu play a central role in coordinating economic linkages between the two regions. Even engineers who remain in Silicon Valley are typically integrated into the transnational community. Many work for start-ups or large firms with activities in both regions. Some moonlight as consultants on product development for Taiwanese firms. Others return to Taiwan regularly for technical seminars sponsored by government agencies or professional associations.

As engineers travel between the two regions they carry technical knowledge as well as contacts, capital, and information about new opportunities and new markets. Moreover, this information moves almost as quickly between these distant regions as it does within Hsinchu and Silicon Valley because of the density of the social networks and the shared identities and trust

1 The incentives include low interest loans, a five-year income tax break for the first nine years of operation, the right to retain earnings of up to $200 \%$ of paid-in capital, accelerated depreciation of R\&D equipment, and low cost land. This information and the data on the Park in the following paragraph comes from the Science Park Administration, Hsinchu Science-Based Industrial Park. 
within the community. These transnational ties have dramatically accelerated the flows of skill, know-how, and market information between the two regions. In the words of a Silicon Valley based Taiwanese engineer:

If you live in the United States its hard to learn what is happening in Taiwan, and if you live in Taiwan its hard to learn what is going on in the U.S. Now that people are going back and forth between Silicon Valley and Hsinchu so much more frequently, you can learn about new companies and new opportunities in both places almost instantaneously. ${ }^{2}$

In the words of another engineer who worked for IBM in Silicon Valley for 18 years before returning to Taiwan: "There's a very small world between Taiwan and Silicon Valley." (Barnathan, 1992) Others say Taiwan is like an extension of Silicon Valley. The former CEO of Acer America claims that the continuous interaction between the Hsinchu and Silicon Valley has generated "multiple positive feedbacks" that enhance business opportunities in both regions. ${ }^{3}$

A closely-knit community of Taiwanese returnees, astronauts, and US-based engineers and entrepreneurs like Miin Wu has become the bridge between Silicon Valley and the comparably sized region that extends from Taipei to the Hsinchu Science Park. By transferring technical know-how, organizational models, and contacts, they have accelerated the upgrading of Taiwan's technological infrastructure — and increased the importance of its suppliers to global production networks. By the end of the 1990s, Taiwan was the world's largest producer of notebook computers and a range of related PC components including motherboards, monitors, scanners, power supplies, and keyboards--and they had the capacity to shift quickly into new products such as wireless phones. (See Figures $2 \mathrm{a} \& 2 \mathrm{~b}$.) And less than two decades after TSMC was founded, Taiwanese firms controlled two-thirds of world foundry capacity, with IC manufacturing capabilities on par with the leading Japanese and US producers.

\footnotetext{
2 C.B Liaw interview, August 28, 1996

3 Ron Chwang interview, March 25, 1997
} 
Figure 2a. Personal Computer OEM Customers and Taiwanese Partners, 1999

\begin{tabular}{|l|l|}
\hline Taiwan Companies & OEM Customers \\
\hline Mitac (Desktop PC) & HP, Compaq \\
\hline FIC (Desktop PC) & HP, Compaq \\
\hline Ta-Tung (Desktop PC) & HP \\
\hline GVC (Desktop PC) & HP \\
\hline Mitac (Notebook PC) & Compaq, HP, SUN \\
\hline Inventec (Server, Desktop PC, Notebook PC) & Compaq \\
\hline Quanta (Notebook PC) & $\begin{array}{l}\text { Dell, Gateway, Apple, Siemens, } \\
\text { IBM, HP }\end{array}$ \\
\hline Arima (Notebook PC) & Compaq \\
\hline FIC (Notebook PC) & NEC Japan \\
\hline Twin-Head (Notebook PC) & NEC, HP, Sharp, Winbook \\
\hline Compal (Notebook PC) & Fujitz, HP, Dell, Toshiba \\
\hline GVC (Notebook PC) & PBNEC \\
\hline Acer (Notebook PC) & Acer/TI, IBM, Apple \\
\hline Alpha-Top (Notebook PC) & Apple, PBNEC \\
\hline Clevo (Notebook PC) & Hitachi, Epson \\
\hline
\end{tabular}

Source: 1. C. Wang, "The Information Technology Industry @ Taiwan”, The Financial Information, Taipei, Taiwan, 1999.

2. "Taiwan Notebook PC is the World No. 1", Global Views Monthly 162,

Taipei, Taiwan, December, 1999.

Figure 2b. Mobile Phone OEM Customers and Taiwanese Partners, 2000

\begin{tabular}{|c|c|c|}
\hline \multirow{8}{*}{$\begin{array}{l}\text { Customer } \\
\text { Motorola }\end{array}$} & Product & Taiwanese OEM Partner \\
\hline & $\begin{array}{l}\text { Mobile Phone } \\
\text { IC Mfg. }\end{array}$ & $\begin{array}{l}\text { DBTEL Inc. (cordless phone); Acer Peripheral } \\
\text { TSMC; UMC }\end{array}$ \\
\hline & PCB & $\begin{array}{l}\text { Wus Printed Circuit Co; United PCB Co. } \\
\text { Zio-De; }\end{array}$ \\
\hline & LED & I-Kwon \\
\hline & Voltage & Fe-Hon \\
\hline & Converter & \\
\hline & Power Supply & Lite-On (power supply, LED) \\
\hline & Panel & Picvue Elec. (LCD/CRT) \\
\hline \multirow[t]{3}{*}{ Ericsson } & PCB & Compeq \\
\hline & Receiver & Mei-Lui \\
\hline & Panel & Compeq (PCB) \\
\hline \multirow[t]{2}{*}{ Alcatel } & Mobile Phone & GVC (Desktop PC, Motherboard) \\
\hline & Panel & Compeq (PCB) \\
\hline \multirow[t]{2}{*}{ Qualcomm } & PCB & Wus Printed Circuit Co. \\
\hline & Panel & Compeq (PCB) \\
\hline
\end{tabular}

Source: Telecommunication Network, Special Edition, Taiwan, 2000. 
The growing integration of the technological communities of Silicon Valley and Hsinchu offers benefits to both economies. Silicon Valley remains the center of new product definition and developer of leading edge technologies, while Taiwan offers world-class manufacturing, flexible development and integration, and access to key customers and markets in China and Southeast Asia. Taiwan has also become a significant and fast-growing source of capital for Silicon Valley-based start-ups. Unlike the arms-length and top down technology transfers between large firms that characterized the relations between Japan and the US in the 1980s, the Silicon Valley-Hsinchu relationship today consists of formal and informal collaborations between individual investors and entrepreneurs, small and medium-sized firms, as well as the divisions of larger companies located on both sides of the Pacific.

In this complex mix, the social and professional ties among Taiwanese engineers at home and their counterparts in the US are often as important as more formal corporate alliances and partnerships. These relationships have been essential to establishing, maintaining, and upgrading Taiwan's role in global production networks--through OEM and ODM relationships and the myriad of other inter-firm partnerships that exploit the distinct and complementary capabilities of Silicon Valley and Hsinchu-based producers.

Taiwan's policymakers created an environment that attracted US-educated engineers to return home in growing numbers, but only after two decades of investment in the domestic environment. The elements of this environment included: a well developed skill base and technical infrastructure, an attractive physical environment for entrepreneurs, a growing venture capital industry, and close professional ties to Silicon Valley. Once in place, the transnational community accelerated the pace of innovation and industrial upgrading of Taiwan's PC and 
semiconductor industries beyond the expectations of the policymakers. This experience suggests that foreign-born engineers are only likely to return permanently to their home countries when they perceive that the professional opportunities outweigh, or at least match, those available to them in the US. ${ }^{4}$

\section{Reversing the Brain Drain? The Case of India and China}

India and China have both suffered greatly from the brain drain. In the 1990s these two countries each sent more students to the US for higher education than any other country. In 1998-99 alone, for example, 10.4\% of international students enrolled in US higher education, or 51,001 students were from China, excluding Hong Kong, and 7.6\%, or 37,482 students were from India (Open Doors, 2000.) The dominance of Chinese and Indian students in US higher education is most pronounced at the doctoral level, and in science and engineering fields in particular. Between 1990 and 1996, 16,749 Chinese and 8,211 Indian students received PhDs in the US, with $92 \%$ of the Chinese and $83 \%$ of Indian degrees in science and engineering (NSF, 1999). See Figure 3.

China and India are therefore particularly well positioned to benefit from "brain circulation" and reversal of the brain drain. Data on the number of foreign students returning from the US to their home countries is limited, however it is clear that students from India and China have tended to remain in the US in greater numbers than their other foreign-born counterparts. An NSF study reports, for example, that in $1996,87 \%$ of Chinese and $84 \%$ of Indian PhD students with temporary work visas planned to stay in the US after graduation, compared with only $48 \%$ of Taiwanese students (NSF, 1999).

\footnotetext{
${ }^{4}$ For more on the Taiwanese case, see Ernst (1999), Saxenian (2000), Hsu (1999.)
} 
Figure 3. Foreign-born PhDs in US, Science \& Engineering: 1985-2000

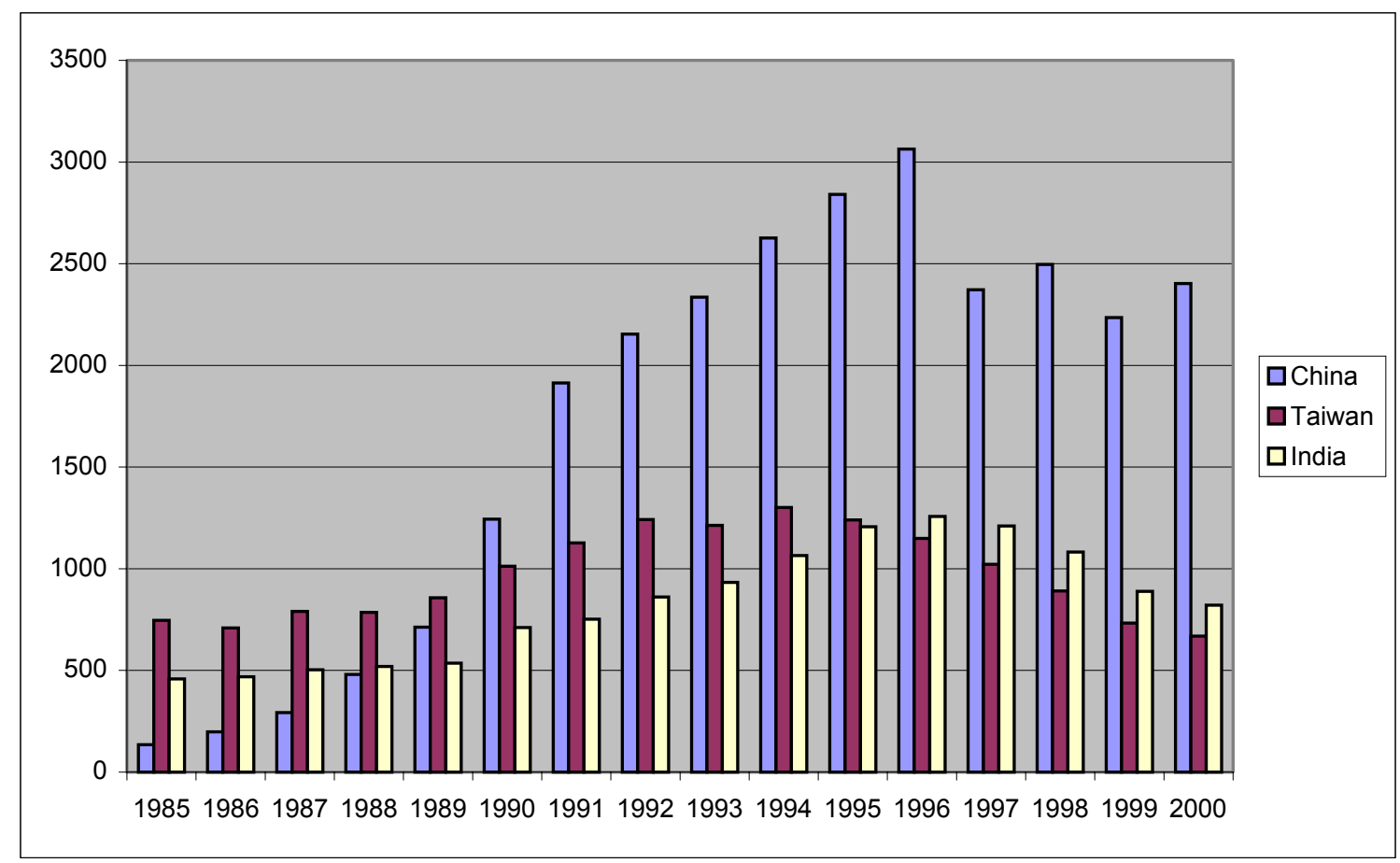

Source: National Science Foundation, 2001

\section{India: From Brain Drain to Brain Circulation}

In the 1970s and 1980s, Indians were second only to Taiwanese as recipients of U.S.

PhDs in engineering and science. The technical and managerial capabilities of these US-educated Indian professionals are clear from their continued entrepreneurial successes in Silicon Valley. By 2000 Indian engineers were at the helm of 972 Silicon Valley-based technology companies, which accounted for approximately $\$ 5$ billion in sales and 25,811 jobs. Moreover, the pace of Indian entrepreneurship accelerated rapidly in the 1990s: while Indians were running only $3 \%$ of the technology companies started between 1980 and 1984, they were running $10 \%$ of those started between 1995 and 2000. (Saxenian, 1999) However, in contrast with their Taiwanese counterparts, few of these highly skilled Indians have returned home to become transnational 
entrepreneurs. Most today play an arms-length role linking US firms with India's software programming skill.

US-educated Indian professionals institutionalized their social networks in the 1990s through the formation of two of Silicon Valley's most vibrant associations: The Indus Entrepreneur (TiE) and the Silicon Valley Indian Professionals Association (SIPA.) $)^{5}$ However they were slow to build direct ties to India. As they gained seniority in US corporations during the 1980s and 1990s many NRIs were instrumental in convincing senior management to establish operations in India to take advantage of the substantial wage differentials for software skill. By the late 1990s, as India's reputation as a supplier of software talent, a large proportion of large American corporations were subcontracting programming to Indian suppliers (an OEM relationship), and most large Silicon Valley technology companies had their own development laboratories in regions like Bangalore.

In 1999 some of Silicon Valley's most successful Indian entrepreneurs began actively build bridges to India. Within two years, TiE had established chapters in Bangalore, Bombay, Delhi, Hyderabad, Calcutta, and Chennai. The growing attention in India to these successful NRI entrepreneurs combined with the market successes of Indian firms like Infosys, Wipro and Satyam created role models for young Indian engineers and contributed to growing interest in IT entrepreneurship. The NRIs in turn invested in promising start-ups and venture funds and begun to serve as role models and advisors for local entrepreneurs.

While traffic between India and the US has increased substantially in the recent years, the great majority of US-educated engineers remain reluctant to return home permanently. There is no data on these trends, but long-time residents of Bangalore report there has still been only "a

5 For more information on the development and organization of the Indian community in Silicon Valley see Saxenian (1999a) 
trickle" of permanent returnees to that city. Interviews in Silicon Valley suggest that Indian professionals in the US are likely to turn to India for software programming and development resources, and that many are interested in working in India for a limited time period, running a US subsidiary or development office. However few have followed the Taiwanese and Chinese pattern of returning home permanently to start new technology companies or work for established or returnee firms.

One of the most significant roles the Silicon Valley community has played in India is in its attempts to influence government policy. In 1999, for example, Silicon Valley entrepreneur K.B. Chandrasekhar led a Committee on Venture Capital for the Securities and Exchange Board of India. The committee's report developed a comprehensive vision for the growth of India's VC industry, and proposed a series of regulatory and institutional reforms to achieve this goal based on a survey of the global experience. 6 They have also convened forums bringing together top policymakers and NRIs to discuss deregulation of the telecommunications industry. Efforts such as these could contribute to the creation of a more attractive context for returning entrepreneurship, particularly if accompanied by other policy reforms directed at improving the local and regulatory environment for innovation.

Indian engineers in Silicon Valley report that business conditions improved dramatically in India in the 1990s. The establishment of the Software Technology Parks (STPs) scheme has provided export-oriented software firms in designated zones tax exemptions for five years and guaranteed access to high-speed satellite links and reliable electricity. The economic liberalization that began in 1991, particularly the removal of duties and licenses on imports of software and industrial equipment, were essential to the growth of the software industry. Yet

6 See the Report of K.B. Chandrasekhar Committee on Venture Capital to the Securities and Exchange Board of India at http://www.sebi.gov.in/ 
even today expatriates complain about bureaucratic restrictions, corrupt and unresponsive officials, and an infrastructure that causes daily frustrations - from unreliable power supplies, water shortages, and backward and costly telecommunications facilities to dangerous and congested highways. ${ }^{7}$

The Indian software industry boomed in the late 1990s, with $\$ 4$ billion in software exports by 2000 , but most of the growth was still driven primarily by low-value added services (Arora et al, 2001). Indian companies have moved beyond body shopping exclusively (hiring low cost Indian programmers to work onsite for foreign customers) and shifted to offshore production (in India) that allows for the local accumulation of experience and learning. Over time, OEM relationships with major US customers have led to significant improvements in quality and the ability to take on increasingly complex projects. ${ }^{8}$ However Indian software companies have been so profitable that they face few incentives to address higher value-added segments of the market--or to support entrepreneurs, either internal or external, to do so. As a result, the industry remains dominated by a small number of large export-oriented corporations who serve as an important node in global production networks, but that have minimal ties with each other, local entrepreneurs, or the science and technology base in India.

India still lacks a critical mass of returnees or transnational entrepreneurs. And there are few Taiwan-style "astronauts" or U.S.-educated Indian engineers who have their feet sufficiently in both worlds to transfer up-to-date information and know-how about markets and technologies or to build the long-term relationships and that would accelerate the upgrading of India's

7 A 1999 study by McKinsey \& Co estimates that as much as \$23b in IT export revenues and 650,000 jobs failed to materialize in India over an 8-year period because of limitations of the telecomm infrastructure.

8 There are more CMM level five companies in India than elsewhere in the world. 
technological infrastructure. This would include not simply transforming the software industry but also developing a viable hardware and manufacturing sector.

Communication between the technology communities India and the US continue to grow. Alumni associations from the Indian Institutes of Technology are starting to organize events in Silicon Valley. Some of the large software companies have established subsidiaries and alliances in the US. And venture capital firms are emerging to invest in firms that link Silicon Valley's technology and market access with India's software skills. So while reversal of the "brain drain" is not yet on the horizon, there is a small but fast growing professional community linking Silicon Valley and regions like Bangalore—one that could play an important role in upgrading the Indian IT sector in the future.

\section{China: Reversing the Brain Drain?}

US-educated students from Mainland China--like their Taiwanese counterparts a decade earlier--started to return home in growing numbers in the late1990s. A survey by the China Research Center and the US International Education Association found that 30,000 (18.8\%) of 160,000 students who studied in the US between 1978 and 1998 had returned to China (World Journal, 8/29/99). A more recent study by the Beijing Science \& Technology Committee claims that 140,000 students returned to China between 1996 and 2000 and that these returnees group had started 3,000 firms with a total output of \$1.B (People's Daily, 1/3/01.) Another report claims that over 20,000 overseas students have returned to Beijing to start companies since 1988. 9 (The findings of the latter studies should be treated with some caution because of their source and more likely reflect trends rather than accurate numbers.)

\footnotetext{
9 People's Daily: http://www.zgc.gov.cn/news/dailynews/000911-4.htm
} 
There have been two observable waves of Chinese returnees from the United States. In the mid and late 1990s, a sizeable cohort of US-educated Mainlanders moved to Beijing to start telecommunications and Internet-related companies, or to run branches of US-based companies targeting the China market. These returnees were typically recent graduates, drawn from all over the U.S., with graduate training in business management or engineering, but limited work experience. One of the most successful firms of this era is AsiaInfo, a NASDAQ-listed company started by returnees from Texas that is now China's largest systems integrator for the telecommunications and Internet industry.

A distinct second, and apparently larger, wave of returnees began in 2000 as a result of substantial foreign investments in semiconductor manufacturing capabilities. The Semiconductor Manufacturing International Corp. (SMIC) and Shanghai Grace Semiconductor Manufacturing Corporation, for example, both of received over US $\$ 1.5$ billion from consortia of US, Taiwanese and Chinese investors to build IC production lines in Shanghai to serve the China market. The returnees joining these ventures likely to be older and more experienced semiconductor engineers and managers from Silicon Valley and/or Taiwan than the earlier wave of Mainland returnees. Hundreds of Silicon Valley and Taiwan-based enterprises in chip design, packaging and testing, equipment installation, and ancillary services have been lured to the region as well, in part by aggressive recruitment by Shanghai officials, constituting an increasingly integrated and complete industrial production chain for microelectronics.

While this certainly does not amount to a full-scale "reversal" of the brain drain, the increasing return of US-educated engineers and scientists educated has contributed greatly to China's growing role in global production networks. In the 1990s Taiwanese PC firms shifted manufacturing of low-end components, such as power supplies, mice, keyboards, cases, and 
monitors, to China, particularly the Dongguan region in Southern China to take advantage of substantially lower cost labor and land (Tong, 2000). ${ }^{10}$

Figure 4. Annual Value of IT Production, Taiwan, 1981-1998

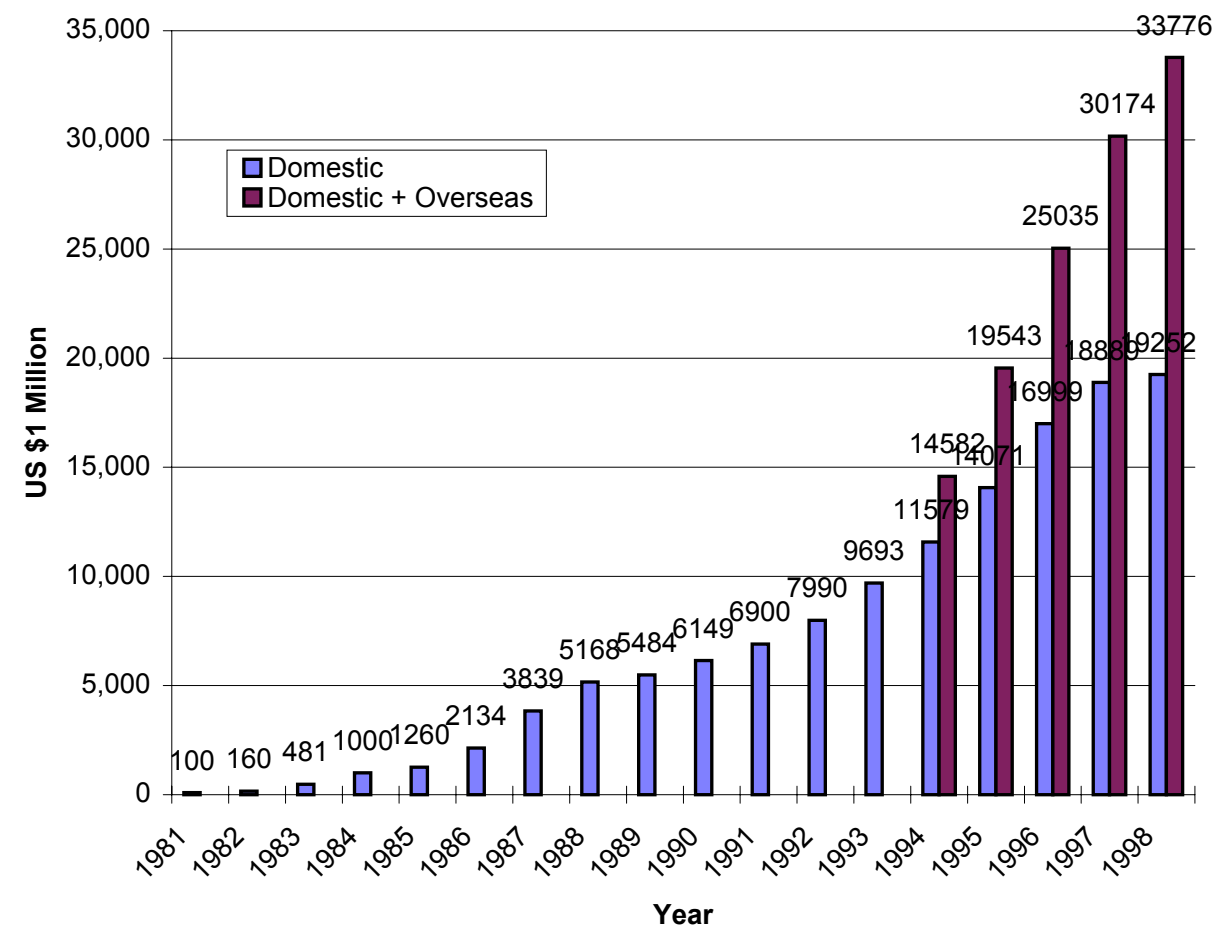

Note: The majority (90\%) of Taiwan's overseas production is in Mainland China

Source: 1. C. Huang, "R.O.C.: Republic of computers", The Common Wealth, Taipei,

Taiwan, 1995.

2. http://mic.iii.org.tw/english/asiait/issues/special/1998/98sp-1.htm

In the late 1990s, Taiwanese producers of higher value-added products such as scanners, motherboards, video card, and laptop computers began shifting activities to China as well, this further north, to Shanghai and nearby Suzhou and Kunshan, in Jiangsu Province. These companies increasingly moved their supplier networks and management teams as well, setting up

10 These high tech Investments represent an extension of the earlier wholesale shift of labor Intensive Taiwanese Industries such as plastic and rubber products, electric and electronic appliances, and garments and footwear In the Pearl River Delta region of Southern China (Chen, 19xx.) 
integrated production centers from which to serve international OEM clients. By 2001, it was estimated that some 250,000 Taiwanese, including the families of plant managers and engineers, were living in the greater Shanghai area.

This latter wave, which has been associated with the merging of Taiwanese and Mainland Chinese transnational communities, appears to be transferring high-level PC and semiconductorrelated skill, know-how and capabilities to Shanghai more rapidly than they were transferred to Taiwan in the 1980s and 1990s. Many observers predict that China will be the world's largest producer of information technology hardware within a decade--and an important new node in the industry's global production networks.

\section{Building the Bridge to Silicon Valley}

Since China began allowing large numbers of students abroad for study in the early 1990s, policymakers have recognized the opportunity to tap this pool of foreign-educated Chinese for domestic development purposes. While the most desirable option would be to recruit all of the "Overseas students" back to China, this initially proved difficult because of the large gap in living and working conditions between China and the more developed West. As a result, local and central governments pursued two types of strategy in attempts to reverse the brain drain:

\section{- Government Support of Technical and Business Exchange}

Chinese policymakers have devoted substantial resources to promoting technical and business exchanges that involve overseas Chinese students. This typically involves events such as conferences, investigation tours, joint research projects, and exhibits. Such activities are designed to involve scientists and researchers, business people, and policy makers in cross- 
regional exchanges of know-how and information. They also provide opportunities for overseas mainland professionals to build relationships with their domestic counterparts. In some cases a local and central government agency will develop a program that directly funds such events, in others it will subsidizes non-government agencies and the private sector to sponsor such activities.

In the late 1990s, Chinese policymakers, academic institutions and technology companies increased their commitment to improving external communications, particularly with Silicon Valley's Chinese community. They sponsored a growing number of events and programs in the US, while also inviting Overseas Chinese academics and industry representatives to China to attend conferences and other events. In addition, the Ministry of Education established the “'Chunhui Program'” to finance short-term trips to China by Overseas Chinese who were trained abroad to participate in technology-associated activities such as conferences, research projects or other authorized programs. Many of Silicon Valley's Chinese professionals have participated in these programs.

\section{- Programs to Encourage Return Entrepreneurship}

Policy makers in China, at both local and central levels, have also attempted to attract overseas students home to start their own technology companies. Representatives of cabinetlevel ministries as well as municipal governments from large cities such as Shanghai and Beijing pay regular visits to Silicon Valley to recruit Chinese technology professionals to return home. The visiting Chinese officials usually hold dinners or meetings with Mainlanders and use the occasion to publicize the favorable policy and business environment in China.

Many municipal governments have established "Returning Students Venture Parks" within the Development Zones of High \& New Technology Enterprise. These parks are exclusively for 
enterprises run by returnees and while they offer infrastructure and financial benefits like other science parks, they also address special needs of returnees, from accelerating bureaucratic processes involved with establishing residency to insuring access to prestigious primary and secondary schools for their children. See Figure 5. 


\section{Figure 5. Distributed electronically to Bay Area China Network (8/11/98) with subject heading: A Great Business Opportunity for You}

\section{A Briefing on China Suzhou Pioneering Park for Overseas Chinese Scholars}

Sponsors:

Chinese Scholarly Exchange Service Center, Ministry of Education

Torch Program Office, Ministry of Science and Technology

Jiangsu Service Center for the Shift of Qualified Personnel

Jiancsu Science and Technology Commission

The Administrative Committee of the Suzhou New Technology District

Suzhou Science and Technology Commission

Location:

The Park is located in the Suzhou New District (Suzhou National New \& High Technology Industrial Development Zone) to the west of the old city proper of

Suzhou. The district is only $80 \mathrm{~km}$ away from Shanghai and 1.5 hour drive from Shanghai Hongqiao Airport.

Mission:

To create a favorable environment for exploitation of research results and development of small and medium-sized technology based enterprises by providing all around service and quality facilities

Target clients:

Technology-based companies and research institutes run by students and scholars studying or working or returned from abroad

Incentives for tenants:

- Three year refund of business tax starting the first day of operation

- Three year-refund of the local part of VAT

- Exemption from income tax in the first two profit-making years, six-year reduction of the rate by $50 \%$ that and then levied at a special rate of $15 \%$ for the next three years

- Minimum registered capital of US $\$ 10,000$ provided for technology consultancy or service provider, US $\$ 60,000$ for manufacturing enterprises

- Application priority for different-level grants and funds

- Application priority for certificate of new \& high technology product/enterprise

- Building management and business services

- $\quad$ Free provision of registration formalities

- Provision of advice on policy and technical issues

- Business promotion

- Assistance in obtaining financing and refunds of duties

- Provision of training programs

Progress to date:

A news conference was held in Beijing this February to declare the establishment of the Park. The six sponsors have jointly set up the Torch New \& High Technology Investment and Guarantee Company and registration is now underway. The company is not-for-profit and will specialize in venture capital and credit guarantees for tenants of the park.

Building:

The park owns one four-story building with floor space of 10,000 square meters. It hosts 88 units ranging from 20 to 100 sq meters. Services and facilities include the following:

-Conference room with conferencing facilities

-Seminar room

-Product display chamber

-Internet access, central air conditioning

-Reception

-Fax, typing , word-processing, and photocopying services

-Air ticket booking, hotel room reservations

-24-hour security services

Applicants and companies:

Til now, the Park has received more than 50 applications and 30 of them are in operation. Business of theses companies mainly covers electronics, biotech, mechanics (sic), computer software, and environmental protection. Presidents or managing directors of these companies have studied in U.S.A., Japan, France, and U.K.

China Suzhou Pioneering Park for Overseas Chinese Scholars invites you to apply today. 
By 2000, there were 23 "Returning Students Science Parks" across China, and many other municipalities had policies to attract returning students but no park. The "Returning Students Science Park" in the Zhongguancun (Haidian) district of Beijing, for example, reports that it housed 48 companies and 68 returning students in 1998. This is the oldest and largest of the three overseas student parks located in Beijing--which collectively housed 114 companies. It is difficult to determine the extent to which such policies toward returning students have contributed to China's success in technology industries, or even to the rate of return of overseas students. However it is worth noting that these policies are quite similar to those policies pursued by Taiwanese policymakers in the 1970s and 1980s that played a central role in the creation of a transnational community linking Taiwan and Silicon Valley.

The evidence from Silicon Valley suggests that Mainland Chinese professionals, like their Taiwanese predecessors, maintain professional as well as personal ties to China even while working in the US. There are half dozen Chinese professional associations in the region that range in size from 200 to over 1000 members. ${ }^{11}$ While originally formed to organize social activities and help new immigrants overcome the feeling of isolation in a foreign culture, they have become important forums for exchanging news, contacts, and business information about China. These associations sponsor regular business tours to China, receive delegations of Chinese government officials, and serve as conduits for Chinese firms recruiting in the Valley. In 1998, for example, the North American Chinese Semiconductor Association co-sponsored a twoweek tour of China's semiconductor industry for a delegation of local engineers. The group produced a scientific report that was widely circulated among Mainland Chinese in the Valley.

11 These are separate from an equal number of Taiwanese professional associations in the Valley. The Taiwanese and Mainland Chinese have established separate organizations for many reasons having to do with history and culture, as well as timing of their arrival in the US, but this may change in the future. 
The alumni associations of the elite Chinese secondary schools such as Beijing University and Qinghua University have active Bay Area chapters that provide an additional direct link back to China.

Mainland Chinese have primarily arrived in the US during the 1990s, and so have started far fewer companies than the Taiwanese and Indian engineers, who began coming to the US in the 1970s. However those who have started companies have focused almost exclusively on developing products and services for the Chinese market. The dominant model among Mainland start-ups is to incorporate in the US and locate headquarters in Silicon Valley while operating primarily in the Mainland. While there may be an R\&D office in Silicon Valley, all other functions are located in China. As a result, these firms have more employees in China than the US, and their top executives spend most of their time in China--or on airplanes between Silicon Valley and China!

UTStarCom, for example, provides telecommunications network infrastructure for the Chinese market. It was started by a US-educated engineer and is headquartered in Silicon Valley, where is has 30 employees, but has 1000 employees in China, making it the third largest producer in Beijing's Zhongguancun Science Park. Sina.com, which has followed a similar model, with its origins and base in Silicon Valley, is now the leading Internet portal in China. Both companies went public on NASDAQ in 2000. Jason Wu's NetFont, an Internet security software products co primarily targeting the mainland market, likewise has 10 people in Silicon Valley and 60 in Beijing. CEO Wu reports that he spends $90 \%$ of his time in the China operations.

In sum, Mainland Chinese engineers returned home at an increasing rate in the late 1990s and early 2000s, spurred at least in part by active recruitment by local and provincial 
governments. Many became entrepreneurs, starting telecommunications and Internet-related companies to serve the domestic Chinese market, while also maintaining close ties to the US. The growth of a transnational community linking Silicon Valley and China parallels that established a decade earlier between Taiwan and Silicon Valley--and is accelerating the creation of information technology-related capabilities in China.

The large-scale commitments made by U.S. and Taiwanese investors in semiconductor manufacturing in 2000 and 2001 illustrate how a transnational community can radically accelerate the emergence of new nodes in the global production networks. As US-educated Mainland Chinese integrated into the technical communities established by their Taiwanese predecessors in the late 1990s, they identified new entrepreneurial opportunities associated with exploiting China's relatively low cost skill base while also targeting the potentially vast domestic market. In this case, the technical and managerial know-how as well as the business and market connections accumulated among the Taiwanese transnational community are being transferred to Shanghai.

As Chinese engineers extend their technical networks from Silicon Valley and Taiwan to the Mainland, they are not only creating an important new global source of information and communications technology-related production, but also further deepening the division of labor and compelling greater specialization of existing nodes in the global production network such as Taiwan and Silicon Valley.

\section{Conclusions}

This paper has explored the close and complementary relationships between transnational communities and global production networks. A transnational technical community is not necessary for a region or nation to participate in global production, but such a community can 
significantly improve a region's position in the global hierarchy by providing a source of worldclass skill and tacit knowledge, as well as close connections to leading edge markets and technologies. At the limit, transnational entrepreneurs supported by a technical community and supportive domestic infrastructure can even establish new flagship companies that destabilize existing hierarchies.

Taiwan, India and China have all emerged as important new nodes for the production of information and communications technologies over the past two decades, but they have followed different trajectories. Taiwan's well-developed transnational community was critical to the formation and subsequent upgrading of a localized cluster of producers, who benefited greatly from direct links to Silicon Valley's technology and markets. A reversal of the brain drain and the growth of transnational entrepreneurship in Taiwan's PC and IC industries in turn accounts for its participation in global networks as a higher-level supplier than many of its East Asian counterparts.

India's emergence as a major exporter of software programming and development skill owes its growth in part to the early contracts provided by the Indian business community in the U.S. And the transnational community that has emerged recently linking Silicon Valley to regions like Bangalore has promoted a beneficial dynamic of "brain circulation." However India has failed to tap large and highly educated pool of US-educated Indian engineers and scientists to become transnational entrepreneurs, and so remains a relatively low value added producer in global production networks.

Finally, China appears poised to follow Taiwan's trajectory a decade later. While the transnational community is in its formative stages the Mainland Chinese have already benefited from growing ties with the Taiwanese technical community. Domestic policymakers have 
aggressively, and apparently successfully, recruited transnational entrepreneurs from Silicon Valley. While there remains uncertainty in the political environment, China has emerged as a node in global production networks with the potential to surpass Taiwan as an international IT manufacturing and logistics center. Indeed, the combination of close ties to Silicon Valley and a huge domestic market means that in time China could even become a source of innovative new flagship companies, not simply a secondary or tertiary tier in global networks.

This paper explores Chinese and Indians transnational communities because they are the largest groups of immigrant engineers in the U.S., and their technical communities are heavily concentrated in Silicon Valley. However other groups of US-educated immigrant engineers provide sources of transnational entrepreneurship. A transnational community of Israeli engineers and entrepreneurs has played a similar role in developing Israel's technology industry-in this case at a higher technological level than either India or Taiwan (Autler, 2000.) Likewise US-educated Irish immigrants have built strong ties to the Boston (Massachusetts) technology community and many have returned home and contributed directly to the growth of Ireland's software and IT industries (O'Riain, 2000.) It would be worthwhile, for example, to explore the experience of Korean and Japanese immigrant engineers and scientists in the U.S. Future research should also explore the nature and extent of transnational communities from other parts of the world that have attracted large numbers of immigrant engineers and scientist, including Australia, the United Kingdom, and Japan.

For policymakers, the lessons from this research are clear. The brain drain offers substantial unintended assets, but only to countries that actively pursue them. By actively recruiting returnees and providing attractive environment for transnational entrepreneurs, policymakers in Taiwan and China have capitalized on their overseas Chinese engineers and 
scientists. Indian policymakers, with a more laissez-faire approach toward the overseas community, have failed to fully exploit this tremendous resource, in part because of failures to improve the domestic infrastructure and regulatory environment. A transnational technical community provides a developing country with privileged connections to world-class technical talent as well as access to the world's leading technology producers. In today's volatile and fastchanging economy, these personal connections are far more flexible and responsive than multinational corporations, and can facilitate the rapid adaptation of domestic capabilities to facilitate the upgrading of the position of local firms in global production networks. 


\section{REFERENCES}

Arora, Ashish, V.S. Arunchalam, Jai Asundi, Ronald Fernandes "The Indian Software Services Industry" Working Paper, Heinz School of Public Policy and Management, Carnegie-Mellon University, 2000

Autler, Gerald "Global Networks in High Technology: The Silicon Valley-Israel Connection" Masters thesis, Department of City and Regional Planning, University of California at Berkeley, Spring 2000

Chang, Shirley L. "Causes of Brain Drain and Solutions: The Taiwan Experience" Studies in Comparative International Development. Spring 1992, 27 (1): 27-43

Chan, Xiangming "The New Spatial Division of Labor and Commodity Chains in the Greater South China Economic Region" in Gary Gereffi, ed. Global Commodity Chains

Dedrick, Jason and Kenneth Kraemer Asia's Computer Challenge: Threat or Opportunity for the United States and the World? NY: Oxford, 1998

Ernst, Dieter and Linsu Kim "Global Production Networks, Knowledge Diffusion, and Local Capability Formation: A Conceptual Framework" East-West Center Working Papers, Economics Series, No. 19, May 2001

Ernst, Dieter. "What Permits David to Defeat Goliath? The Taiwanese Model in the Computer Industry" Berkeley: Unpublished Paper, BRIE, University of California at Berkeley, 1998

Greico, Joseph M. Between Dependency and Autonomy: India's Experience with the International Computer Industry Berkeley: University of California Press, 1984

Gu, Shulin China's Industrial Technology: Market Reform and Organizational Change London: Routledge, 1999

Heeks, Richard. India's Software Industry: State Policy, Liberalisation and Industrial Development New Delhi: Sage Publications, 1996.

Hsu, Jinn-yuh. “A Late Industrial District? Learning Networks in the Hsinchu Science-Based Industrial Park” Berkeley: Doctoral Dissertation, Geography, University of California at Berkeley, 1997

Kogut, Bruce and Udo Zander "Knowledge of the Firm and the Evolutionary Theory of the Multinational Corporation Journal of International Business Studies 24, 4, 1993

Krueger, Anne O. and Sajjid Chinoy "The Indian Economy in a Global Context" Background paper, Conference on Indian Economic Prospects: Advancing Policy Reform. Center for Research on Economic Policy Reform, Stanford University, May 31-June1, 2000 
Lu, Qiwen China's Leap into the Information Age: Innovation and Organization in the Computer Industry Oxford: Oxford University Press, 2000

Lu Qiwen and William Lazonick "The organization of innovation in a transitional economy: business and government in Chinese electronic publishing" Research Policy 2000

Mathews, John A. “A Silicon Valley of the East: Creating Taiwan's Semiconductor Industry" California Management Review._v. 39, n. 4, Summer 1997

Naughton, Barry, ed. The China Circle: Economics and Technology in the PRC, Taiwan and Hong Kong. Washington, D.C.: Brookings Institution Press, 1997

National Association of Software and Service Companies, The Software Industry in India: A Strategic Review New Delhi: NASSCOM, 1999, 2000 http://www.nasscom.org

National Association of Software and Service Companies, Indian IT Strategies, Report prepared by McKinsey \& Co., New Delhi: NASSCOM, 1999

National Science Foundation, Division of Science Resource Studies, Statistical Profiles of Foreign Doctoral Recipients in Science and Engineering: Plans to Stay in the United States" NSF 99-304, Author, Jean M. Johnson (Arlington, VA, November 1998)

O'Riain, Sean "The Flexible Developmental State: Globalization, Information Technology, and the 'Celtic Tiger"' Doctoral dissertation, Sociology Department, University of California at Berkeley, 2000

Parthasarathy, Balaji "Globalization and Agglomeration in Newly Industrializing Countries: The State and the Information Technology Industry in Bangalore, India" Doctoral dissertation, University of California at Berkeley, Spring 2000

Portes, Alejandro. "Global Villagers: The Rise of Transnational Communities" The American Prospect. pp. 74-77, March-April 1996

Saxenian, AnnaLee Silicon Valley's New Immigrant Entrepreneurs San Francisco: Public Policy Institute of California, 1999 http://www.ppic.org/publications/PPIC120/ppic120.abstract.html

Saxenian, AnnaLee "The Silicon Valley-Hsinchu Connection: Technical Communities and Industrial Upgrading" Discussion Paper, Stanford Institute of Economic Policy Research, Stanford University, 2000

Saxenian, AnnaLee "The Bangalore Boom: From Brain Drain to Brain Circulation?" in Kenneth Keniston and Deepak Kumar, eds. Bridging the Digital Divide: Lessons From India Bangalore: National Institute of Advanced Study, forthcoming.

Saxenian, AnnaLee and Chuen-Yueh Li "Bay-to-Bay Strategic Alliances: The Network Linkages Between Taiwan and the U.S. Venture Capital Industries" International Journal of Technology Management, forthcoming 
Schware, Robert "Software Industry Entry Strategies for Developing Countries: A 'Walking on Two Legs' Proposition" World Development. 1992 Vol 20, No 2 :143-164

Securities and Exchange Board of India "Report of K.B. Chandrasekhar Committee on Venture Capital" New Delhi, SEBI, 2000 http://www.sebi.gov.in

Tong, Xin "Global-local Networking of PC Manufacturing in Dongguan, China" Unpublished paper, Beijing University, Department of Geography, 2000.

Yu, Guoqiang "Chinese Immigrants in Silicon Valley and Innovation in China: A Case Study of Beijing Science Park" Advanced Policy Study submitted to the School of Public Policy, University of California at Berkeley, Spring 2000 